\title{
Nurses Attitudes Toward Cancer and Affecting Factors
}

\author{
(1) Emine Derya isTER, ${ }^{1}$ (1) Yasemin ALTINBAŞ² \\ 'Department of Nursing, Kahramanmaraş Sütçü İmam University, Kahramanmaraş-Turkey \\ ${ }^{2}$ Department of Nursing, Adıyaman University, Adıyaman-Turkey
}

\begin{abstract}
OBJECTIVE
The aim of this study was to determine nurses' attitudes towards cancer and affecting factors.

\section{METHODS}

The population of this descriptive research was composed of nurses working in Public Hospitals in Adiyaman city center. The study was conducted with 214 participants.

\section{RESULTS}

The mean scores of factor 1, factor 2, factor 3 and total QMATC scores are $1.72 \pm 0.67,1.89 \pm 0.51$, $1.53 \pm 0.47$ and $1.71 \pm 0.42$, respectively. It was found that nurses who encontered cancer patients in their close social circles such as neighbors and friends had higher impossibility of recovery-stereotyping scores than those who never encountered cancer cases. $(\mathrm{p}<0.05)$.
\end{abstract}

\section{CONCLUSION}

It was observed that the nurses working in the hospital had positive attitudes towards the factors of revealing and spreading the diagnosis of cancer, impossibility of recovery-stereotyping and discrimination against cancer patients.

Keywords: Attitude; cancer; nurse.

Copyright $\odot$ 2021, Turkish Society for Radiation Oncology

\section{Introduction}

According to the definition of the World Health Organization (WHO), cancer is a group of diseases characterized by uncontrolled cell proliferation as a result of genetic changes in cells.[1] Cancer is one of the most important health problems today; it ranks the second most common cause of death following cardiovascular diseases in many countries of the world and also in Turkey.[2] With the emergence of new diagnosis and treatment methods, increased opportunities to benefit from health institutions and prolonged average life expectancy, cancer becomes increasingly important, and the number of diagnosed cancer cases increases every year.[3]
In 2008, 12.4 million people were diagnosed with cancer and 7.6 million people died due to cancer. It is estimated that deaths caused by cancer will continue to increase worldwide and that 12 million cancer deaths will occur in 2030. [4] 53.0\% of new cancer cases and $60.0 \%$ of deaths occur in under developed countries.[5] The average incidence of cancer in our country is 196 per hundred thousand. The number of cancer cases is 256.4 per 100.000 males and 158.1 per 100.000 females. Given the current increase rates, it is estimated that the incidence of cancer in our country will double in the 2030s and reach 450 per hundred thousand.[5]

There are more than one hundred known cancer types. In Turkey, the most common types of cancer 
that cause death are lung-trachea-bronchus, stomach, bladder, colorectal cancers, leukemia and multiple myeloma.[4] In the coming years, treating a large number of cancer patients with the aspects of diagnosis, providing palliative, supportive care and end-of-life care will become a major challenge for many countries. [5] Care for cancer patients requires a multidisciplinary approach and nurses are an important and integral element of cancer care. Nurses provide multi-directional care at the stages of promotion and protection of health, diagnosis, treatment, rehabilitation and palliation. [6] Clinical practice, training, counseling, and management, as well as participation in clinical research on cancer have expanded the fields of nursing.[7] Nurses work with cancer patients and their relatives in many places such as reference hospitals, medical centers, oncology units, services, polyclinics, doctor offices, home care, and hospice centers. Nursing has many subspecialties such as bone marrow transplantation, radiotherapy, surgical oncology, community education, genetic risk counseling, and prevention programs. In all these settings, the general aim of the nurses is to ensure that the patient and his/ her family maintain their functions at the highest level and to improve their quality of life.[8] Understanding nurses' attitudes towards cancer while fulfilling all these roles provides a basis for cancer patient care programs. A better understanding of nurses' beliefs and attitudes towards cancer is also important in developing issues related to patient care quality, public awareness and cancer screening and treatment protocol. $[7,8]$ In addition, it is thought that the attitudes and behaviors of nurses who spend more time and communicate with their relatives during the disease process may affect the patient's coping mechanism positively or negatively. In the effective struggle against cancer, the existing knowledge, attitudes and behaviors of the nurses who provide care should be determined and then appropriate trainings should be given to increase the cancer awareness level of the nurses. As a result of the literature review; there were no studies found investigating whether there is a change in the attitudes and behaviors of the nurses who care for patients who are diagnosed with cancer, whose cancer treatment is continuing or whose cancer treatment is completed. For this reason, this study aimed to flash on understanding the nurses' evaluations about cancer and cancer patients, the needs and content of cancer education and information programs, and the psychosocial processes and situations of the families of these individuals in the disease period. Therefore, the aim of this study is to determine nurses' attitudes towards cancer and the factors affecting them.

\section{Materials and Methods}

\section{Study Design and Subjects}

This descriptive cross-sectional study was conducted in the provincial center of Adiyaman, located in the southeast of Turkey. The population of the study consisted of 237 nurses working in a public hospital located in the provincial center of Adiyaman. The sample size of the study was 177 as calculated based on an effect size of 0.3 , an error level of $5 \%$, and a confidence level of $95 \%$ and a power of $95 \%$. Since three nurses were on unpaid leave, five nurses were on sick leave, eight nurses were on maternity leave and seven nurses were not willing to participate in the study, the research was completed with 214 participants.

\section{Data Collection}

The research data were collected between 15 May and 15 August 2018. In data collection, "Individual Identification Form" and the "Questionnaire for Measuring Attitudes Toward Cancer (QMATC)" were used. The individual identification form contains 13 questions regarding the sociodemographic characteristics of nurses and information about their cancer attitudes. The QMATC was developed by Cho et al.[9] (2013) to measure the attitudes of cancer patients' relatives and related individuals in the public, and in our country the validity and reliability study was conducted by Yllmaz et al.[10] (2017) on Turkish public. It provides information about the positive/negative attitudes of individuals living in public. The QMATC consists of 12 items and three sub-factors. The first factor is "Willingness to disclose a cancer diagnosis", the second factor is the "Impossibility of recovery-stereotyping", and the third factor is the "Discrimination against cancer patients". The Cronbach's alpha value of the scale is 0.92 in the Turkish society and the Cronbach's alpha value was found as 0.85 in the nursing group in this study. The mean score of the items is used in the assessment of the scale, and the scores of 2.5 and above indicate the presence of negative attitudes towards cancer.[9]

\section{Ethical Aspect of Research}

To conduct this study, permission of the Non-invasive Research Ethics Committee of Adiyaman University (2018/3-18) was obtained. Written permissions were obtained from the hospital where the study was conducted and the participant nurses. 


\section{Statistical Analysis}

Statistical Package for the Social Sciences (SPSS 17.00) was used for statistical analysis of the data. In the evaluation of the data, descriptive statistical methods such as number, percentage and mean were used, and t-test analysis and one-way analysis of variance were used in independent groups.

\section{Data Availability Statement}

The data that supports the findings of this study are available in the supplementary material of this article.

\section{Results}

It was determined that $57.3 \%$ of the nurses participating in the study were in the range of $30-40$ years, $85.5 \%$ were female, $69.2 \%$ were university graduates, $79.4 \%$ were married, $70.6 \%$ had children, and $42.5 \%$ were working shift and only in daytime. It was found that $25.7 \%$ of the nurses had a family member with cancer, $57.9 \%$ of them had a relative with cancer and $75.7 \%$ of them had a friend with cancer. It was found that $73.4 \%$ of the nurses never worked in oncology clinics and $18.7 \%$ of them did never provide care to cancer patients (Table 1).

The mean scores of QMATC and sub-factors and distribution of items were given in Table 2. The mean scores of factor 1, factor 2, factor 3 and total QMATC scores are $1.72 \pm 0.67,1.89 \pm 0.51,1.53 \pm 0.47$ and $1.71 \pm 0.42$, respectively. The fact that the mean score of nurses was below 2.5 for all three factors indicates that the nurses generally do not have negative attitudes towards cancer. $\% 29.4$ of the nurses were agreed that the ability of cancer patients to perform tasks at the workplace may decrease even after successful cancer treatment (Table 2).

Age, gender, marital status, education level, having children, working shifts, presence of cancer patients in their family and among their relatives do not affect the nurses' attitudes towards cancer ( $p>0.05$ ). It was determined that the mean scores of willingness to disclose a cancer diagnosis and discrimination against cancer patients of the nurses with oncology clinical experience were statistically significantly lower than those who have no experience $(\mathrm{p}<0.05)$. This finding indicates that nurses with oncology experience have more positive attitudes towards cancer than those who have no experience. It was found that the mean score of factor 2 (Impossibility of recovery-stereotyping) of the nurses who had cancer patients in their social circles such as neighbors, and friends was higher than other nurses

\begin{tabular}{|c|c|c|}
\hline Specification & $\mathbf{n}$ & $\%$ \\
\hline \multicolumn{3}{|l|}{ Age } \\
\hline $19-29$ & 67 & 31.3 \\
\hline $30-40$ & 115 & 57.3 \\
\hline$\leq 41$ & 32 & 15.0 \\
\hline \multicolumn{3}{|l|}{ Gender } \\
\hline Female & 183 & 85.5 \\
\hline Male & 31 & 14.5 \\
\hline \multicolumn{3}{|l|}{ Education level } \\
\hline High school degree & 32 & 15.0 \\
\hline Associate degree & 34 & 15.9 \\
\hline University degree & 148 & 69.2 \\
\hline \multicolumn{3}{|l|}{ Marrital status } \\
\hline Married & 170 & 79.4 \\
\hline Single & 44 & 20.6 \\
\hline \multicolumn{3}{|l|}{ Parental status } \\
\hline Yes & 151 & 70.6 \\
\hline No & 63 & 29.4 \\
\hline \multicolumn{3}{|l|}{ Working shift } \\
\hline Only daytime & 91 & 42.5 \\
\hline Only night & 32 & 15.0 \\
\hline Shift & 91 & 42.5 \\
\hline \multicolumn{3}{|c|}{ Does anyone in the family have cancer? } \\
\hline Yes & 55 & 25.7 \\
\hline No & 159 & 74.3 \\
\hline \multicolumn{3}{|c|}{ Does any of your relatives have cancer? } \\
\hline Yes & 124 & 57.9 \\
\hline No & 90 & 42.1 \\
\hline \multicolumn{3}{|c|}{ Are any friends or neighbors cancer patients? } \\
\hline Yes & 162 & 75.7 \\
\hline No & 52 & 24.3 \\
\hline \multicolumn{3}{|c|}{ Working status in oncology clinics } \\
\hline Yes & 57 & 26.6 \\
\hline No & 157 & 73.4 \\
\hline \multicolumn{3}{|c|}{ Caregiving status for cancer patient } \\
\hline No & 40 & 18.7 \\
\hline Rarely & 42 & 19.6 \\
\hline Sometimes & 58 & 27.1 \\
\hline Often & 47 & 22.0 \\
\hline Very often & 27 & 12.6 \\
\hline
\end{tabular}

$(p<0.05)$. This finding indicates that the nurses who have cancer patient in their social environment (except for family and relatives) have more negative attitudes towards cancer (Table 3).

It was determined that $11.7 \%$ of the nurses had negative attitude towards "Willingness to disclose a cancer diagnosis" and $8.9 \%$ of them had negative attitudes towards "Impossibility of recovery-stereotyping". It was observed in our study that the number of nurses who have negative attitudes towards cancer was low and that 
Table 2 Nurses' participation items of QMATC and the average of sub-factors and total QMATC

$\begin{array}{ccccc}\begin{array}{c}\text { Strongly } \\ \text { disagree }\end{array} & \begin{array}{c}\text { Disagree } \\ \mathbf{n}(\%)\end{array} & \begin{array}{c}\text { Agree } \\ \mathbf{n}(\%)\end{array} & \begin{array}{c}\text { Strongly agree } \\ \mathbf{n}(\%)\end{array} & \begin{array}{c}\text { Mean } \\ \text { (SD) }\end{array} \\ & & & & \end{array}$

Willingness to disclose a cancer diagnosis (Factor 1)

if I'm diagnosed with cancer, I don't tell my family

If I'm diagnosed with cancer, I don't tell my friends.

If I'm diagnosed with cancer, I don't tell my neighbors.

if I'm diagnosed with cancer, I don't tell my colleagues/Coworkers

Impossibility of recovery-stereotyping (Factor 2)

It is very difficult to be healthy again once a person is diagnosed

with cancer.

Cancer patients would not be socially active once diagnosed with cancer.

The ability of cancer patients to perform tasks at the workplace

may decrease even after successful cancer treatment.

It is impossible to treat cancer regardless of highly developed

medical science.

$\begin{array}{ccccc}99(46.3) & 91(42.5) & 20(9.3) & 4(1.9) & 1.72 \pm 0.67 \\ 87(40.7) & 108(50.5) & 16(7.5) & 3(1.4) & \\ 82(38.3) & 98(45.8) & 28(13.1) & 6(2.8) & \\ 92(43.0) & 105(49.1) & 13(6.1) & 4(1.9) & \\ & & & & 1.89 \pm 0.51 \\ 54(24.8) & 128(59.8) & 28(13.1) & 5(2.4) & \\ & & & & \\ 67(31.3) & 129(6.3) & 14(6.5) & 4(1.9) & \\ & & & & \\ 39(18.2) & 109(50.9) & 63(29.4) & 3(1.4) & \\ & & & & \\ 61(28.5) & 114(53.3) & 31(14.5) & 8(3.7) & \\ 121(56.5) & 87(40.7) & 4(1.9) & 2(0.9) & \\ & & & & 1.53 \pm 0.47 \\ 112(52.3) & 92(43.0) & 8(3.7) & 2(0.9) & \\ 124(57.9) & 86(40.2) & 2(0.9) & 2(0.9) & \\ 121(56.5) & 87(40.7) & 4(1.9) & 2(0.9) & \\ & & & & \end{array}$

Cancer patients would not be able to make contributions to society

Discrimination against cancer patients (Factor 3)

I feel uncomfortable when I am with cancer patients.

I tend to avoid interacting with neighbors who have cancer.

I would avoid working with people who have cancer.

Total

In this study, the mean score of the total QMATC of

the majority of them had a positive attitude towards cancer. \%98.6 of the nurses didn't have discriminative attitudeagainst cancer patients (Table 4).

\section{Discussion}

Cancer is one of the leading causes of death worldwide and all nurses may have to provide care for cancer patients at some point in their career.[11] Kearney et al. (2003) revealed that many health professionals had negative attitudes towards cancer independent of gender, occupational and clinical experience. It has been found that negative attitudes and perceptions towards cancer, and cancer experience of the cancer patient and their families affect the coping strategies, motivation and caregiving behaviors of nurses.[12] In this context, it is not sufficient that only nurses have positive attitudes towards cancer; however, it is also important that cancer patients and their families have positive attitudes towards cancer. Nurses should provide care for cancer patients by considering attitudes of them and their families and plan the initiatives to change negative attitudes. Indeed, Cho et al. (2013) reported that $30 \%$ of patients had negative attitudes towards cancer in the study conducted with 466 cancer patients.[13] the nurses was $1.71 \pm 0.42$, indicating nurses generally did not have negative attitudes towards cancer. There are a few studies which have examined Turkish nurses' attitudes towards cancer or patients with cancer.[14-16] A study that aimed to assess Turkish nurses' attitudes toward cancer and patients with cancer indicated that Turkish nurses hold positive attitudes towards cancer and patients with cancer.[16] In the study by YildirimUsta et al.[14] the nurses were aware of their attitudes towards being positive with cancer patients and its significance in support for cancer patients. Adversely, in a few studies it was demonstrated that health care professionals hold negative attitudes towards patients with cancer.[12,17,18] Nurses' positive attitudes towards cancer patients and their satisfactory work ethics in nursing care provide positive outcomes in patients.

In this study, the mean score of the nurses for the sub-factor "Impossibility of recovery-stereotyping" (Factor 2) was $1.89 \pm 0.51$, indicating that the nurses did not have negative attitudes. In the literature, there are a lot of studies on the attitudes of nurses toward the treatment of cancer and the management of cancer pain.[19-21] Box and Anderson reported that nurses working in the community services such as school 
Table 3 Comparison of QMATC factors of nurses with some variables

\begin{tabular}{|c|c|c|c|}
\hline & Factor 1 & Factor 2 & Factor 3 \\
\hline \multicolumn{4}{|l|}{ Gender* } \\
\hline Female & $1.71 \pm 0.67$ & $1.91 \pm 0.52$ & $1.52 \pm 0.48$ \\
\hline \multirow[t]{2}{*}{ Male } & $1.75 \pm 0.65$ & $1.78 \pm 0.45$ & $1.56 \pm 0.47$ \\
\hline & $p=0.794$ & $\mathrm{p}=0.219$ & $p=0.643$ \\
\hline \multicolumn{4}{|l|}{ Education Level** } \\
\hline High School degree & $1.50 \pm 0.46$ & $1.93 \pm 0.53$ & $1.45 \pm 0.49$ \\
\hline Associate degree & $1.77 \pm 0.77$ & $1.75 \pm 0.59$ & $1.50 \pm 0.55$ \\
\hline \multirow[t]{2}{*}{ University degree } & $1.75 \pm 0.67$ & $1.91 \pm 0.49$ & $1.55 \pm 0.46$ \\
\hline & $p=0.129$ & $p=0.254$ & $p=0.571$ \\
\hline \multicolumn{4}{|l|}{ Marrital status* } \\
\hline Married & $1.70 \pm 0.68$ & $1.89 \pm 0.51$ & $1.53 \pm 0.48$ \\
\hline \multirow[t]{2}{*}{ Single } & $1.72 \pm 0.63$ & $1.90 \pm 0.51$ & $1.51 \pm 0.45$ \\
\hline & $p=0.566$ & $p=0.914$ & $p=0.787$ \\
\hline \multicolumn{4}{|l|}{ Parental status* } \\
\hline Yes & $1.69 \pm 0.68$ & $1.86 \pm 0.50$ & $1.51 \pm 0.48$ \\
\hline \multirow[t]{2}{*}{ No } & $1.79 \pm 0.64$ & $1.95 \pm 0.54$ & $1.58 \pm 0.46$ \\
\hline & $p=0.307$ & $p=0.226$ & $p=0.335$ \\
\hline \multicolumn{4}{|l|}{ Working shift ${ }^{* *}$} \\
\hline Only daytime & $1.63 \pm 0.66$ & $1.85 \pm 0.48$ & $1.46 \pm 0.44$ \\
\hline Only night & $1.75 \pm 0.76$ & $1.88 \pm 0.50$ & $1.53 \pm 0.57$ \\
\hline \multirow[t]{2}{*}{ Shift } & $1.79 \pm 0.64$ & $1.93 \pm 0.55$ & $1.60 \pm 0.47$ \\
\hline & $p=0.288$ & $p=0.514$ & $p=0.136$ \\
\hline \multicolumn{4}{|c|}{ Does anyone in the family have cancer?* } \\
\hline Yes & $1.68 \pm 0.51$ & $1.90 \pm 0.50$ & $1.56 \pm 0.49$ \\
\hline \multirow[t]{2}{*}{ No } & $1.73 \pm 0.69$ & $1.88 \pm 0.51$ & $1.51 \pm 0.47$ \\
\hline & $p=0.660$ & $p=0.783$ & $p=0.510$ \\
\hline \multicolumn{4}{|c|}{ Does any of your relatives have cancer?* } \\
\hline Yes & $1.71 \pm 0.64$ & $1.91 \pm 0.53$ & $1.51 \pm 0.48$ \\
\hline \multirow[t]{2}{*}{ No } & $1.73 \pm 0.70$ & $1.86 \pm 0.48$ & $1.55 \pm 0.48$ \\
\hline & $p=0.857$ & $p=0.533$ & $p=0.494$ \\
\hline \multicolumn{4}{|c|}{ Are any friends or neighbors cancer patients?* } \\
\hline Yes & $1.71 \pm 0.65$ & $1.94 \pm 0.53$ & $1.56 \pm 0.46$ \\
\hline \multirow[t]{2}{*}{ No } & $1.74 \pm 0.73$ & $1.73 \pm 0.42$ & $1.43 \pm 0.51$ \\
\hline & $p=0.810$ & $p=0.009$ & $p=0.096$ \\
\hline \multicolumn{4}{|c|}{ Working status in oncology clinics } \\
\hline Yes & $1.53 \pm 0.57$ & $1.88 \pm 0.55$ & $1.39 \pm 0.40$ \\
\hline \multirow[t]{2}{*}{ No } & $1.78 \pm 0.69$ & $1.89 \pm 0.50$ & $1.58 \pm 0.50$ \\
\hline & $p=0.014$ & $p=0.935$ & $p=0.013$ \\
\hline \multicolumn{4}{|c|}{ Caregiving status for cancer patient** } \\
\hline No & $1.81 \pm 0.80$ & $1.90 \pm 0.54$ & $1.55 \pm 0.46$ \\
\hline Rarely & $1.76 \pm 0.76$ & $1.93 \pm 0.45$ & $1.59 \pm 0.53$ \\
\hline Sometimes & $1.69 \pm 0.51$ & $1.97 \pm 0.51$ & $1.60 \pm 0.44$ \\
\hline Often & $1.66 \pm 0.59$ & $1.86 \pm 0.41$ & $1.46 \pm 0.41$ \\
\hline \multirow[t]{2}{*}{ Very often } & $1.66 \pm 0.75$ & $1.68 \pm 0.67$ & $1.37 \pm 0.57$ \\
\hline & $p=0.196$ & $\mathrm{p}=0.812$ & $p=0.187$ \\
\hline
\end{tabular}

*Student t test independent groups; ** One-way ANOVA

health nurses and visiting nurses have negative attitudes towards the effectiveness of cancer treatment. [20] Shahriary et al.[19] (2015) report that oncology nurses' attitudes towards the pharmacological treatment of cancer pain are poor and their knowledge is insufficient. Likewise, in the study conducted by Ylldirım 
Table 4 Distribution of nurses with negative attitudes towards cancer

\begin{tabular}{lcc} 
QMATC Factors & $\mathbf{n}$ & $\%$ \\
\hline $\begin{array}{l}\text { Willingness to disclose a cancer } \\
\text { diagnosis/Negative Attitude }\end{array}$ & & \\
$\quad$ No & 189 & 88.3 \\
$\quad$ Yes & 25 & 11.7 \\
$\begin{array}{l}\text { Impossibility of Recovery- } \\
\text { Stereotyping/Negative Attitude }\end{array}$ & & \\
$\quad$ No & & \\
$\quad$ Yes & 195 & 91.1 \\
Discrimination Against Cancer & 19 & 8.9 \\
Patients/Negative Attitude & & \\
$\quad$ No & & \\
$\quad$ Yes & 211 & 98.6 \\
& 3 & 1.4 \\
\hline
\end{tabular}

et al.[21] (2008) with oncology nurses in Turkey, it was found that nurses' knowledge and attitudes regarding cancer treatment were insufficient.

In this study, the mean score of nurses regarding the sub-factor "Discrimination against cancer patients" (Factor 3) was $1.89 \pm 0.51$, indicating that nurses did not have negative attitudes. In the study performed by Cho et al.[13] (2013) on 466 cancer patients, it was reported that $10 \%$ of patients are exposed to social discrimination due to cancer and $24.5 \%$ of them have clinically significant depressive symptoms. In the same study, the patients who experienced cancer stigma were reported to be 2.5 times more prone to depression. Holistic care philosophy is important in nursing. Holistic nursing care is a nursing practice that argues the body, mind, spirit, emotions, environment, relationships and social, cultural aspects of life are interconnected and should be addressed as a whole.[22] The negative attitude of nurses towards cancer also affects the patients they care for. While the nurses with negative attitudes towards cancer can provide the physical care to the cancer patient, they cannot provide the care that the patient needs psychologically.[23] In a study conducted by Badihian et al.[24] (2017), it is reported that individuals in society, in some sense the society itself, have/has negative attitudes towards cancer. Negative attitudes of society can lead to discrimination against cancer patients. Yllmaz et al. (2017) reported that the mean score of discrimination (factor 3 ) factor of the participants is high $(2.68 \pm 0.71)$ in the study they conducted with cancer patients and individuals in society in Turkey. [10] For this reason, nurses should be able to evaluate cancer patients who experience discrimination, provide the psychological care that the patient needs, and cooperate with other health professionals in order to provide holistic care.

In the current study, significant relationships were observed between nurses' attitudes toward cancer and working status in oncology clinics and having any friends or neighbors as cancer patients $(\mathrm{p}<0.05)$. Lebovits et al. stated that having oncology course and medical education about oncology can affect attitudes toward cancer.[25] Dedeli et al.[16] found significant relationships between nurses' attitudes toward cancer and patients with cancer and status of giving care for patients with cancer.

In the current study,there was no significant relationship found between nurses' attitudes toward cancer and gender, marital status, education level, parental status, working shifts, presence of cancer patients in family and relatives ( $p>0.05)$. In a study with Turkish nurses, it was shown that there was no significant relationship between nurses' attitudes towards cancer and their educational status, gender and marital status.[16]

In the literature, the questionnaires structured with in-depth interview techniques were used to evaluate nurses' attitudes towards cancer.[18] Attitudes are the whole of beliefs regarding people, objects or thoughts. Attitudes are acquired through learning and can be changed throughout life.[26] Nurses are the members of the society they live in and their attitudes towards cancer can be affected by the society and culture they live in. In the literature, the QMATC was developed to measure the attitudes of individuals in society towards cancer.[9] However, there is no study evaluating nurses' attitudes towards cancer using the QMATC. In this study, the attitudes of the nurses towards cancer were evaluated by using the QMATC and it was found that the Cronbach's alpha coefficient of the scale in nurses was 0.85 . This study indicates that the use of the QMATC in nurses is reliable.

\section{Study Limitations}

The lack of male respondents and the greater number of females in the sample may have resulted in some bias in the results. However, the sample does reflect the gender balance within health care.

\section{Conclusion}

Cancer prevention education and services may prevent disease occurrence or may improve patient outcome by early disease detection and intervention. Oncology nurses are crucial members of the health care team, from cancer prevention and detection through end-of- 
life. Highly skilled oncology nurses take the patient history; assess the patient for cancer related problems and issues; educate the patient, families, caregivers, and communities; provide treatment and care; and offer support and encouragement. Primary care nurses are usually the first point of contact that patients have within the health care system. These nurses take the patient history and emphasize the need for cancer prevention.[27] So, It is important determining nurses attitudes toward cancer. In this study, it was observed that the nurses working in the hospital had positive attitudes towards the factors of revealing and spreading the diagnosis of cancer, impossibility of recovery-stereotyping and discrimination against cancer patients. It was concluded that the nurses in the study had positive attitudes towards cancer in general while a small number of nurses had negative attitudes towards cancer. It was observed that the attitudes of nurses working in oncology clinics towards cancer were more positive. Age, gender, marital status, education level, having children, working shifts, presence of cancer patients in families and among relatives did not affect nurses' attitudes towards cancer. There are few studies conducted to determine the attitudes of nurses towards cancer. For this reason, it is recommended to conduct similar studies in different samples.

Nurses play an important role in prevention of cancer, raising awareness of society regarding cancer, and early diagnosis, treatment, and rehabilitation of the disease. According to the findings of this study, nurses' attitudes towards cancer were positive in contrast to the society they were in. The fact that society has a negative attitude towards cancer can be an obstacle to early diagnosis and treatment of cancer, however, nurses can play a key role in changing society's negative attitudes towards cancer. In particular, the nurses working in the field of public health and clinical nurses can raise awareness in the communities they live in and positively affect the negative attitude of society.

Peer-review: Externally peer-reviewed.

Conflict of Interest: The authors declare that there is no conflict of interest regarding the publication of this article.

Ethics Committee Approval: To conduct this study, permission of the Non-invasive Clinical Research Ethics Committee of Adiyaman University (No. 2018/3-18, Date: 17.04.2018) was obtained. Written permissions were obtained from the hospital where the study was conducted and the participant nurses.

Financial Support: This research did not receive any financial support.
Authorship contributions: Concept - E.D.İ., Y.A. Design - E.D.I.., Y.A.; Supervision - E.D.İ., Y.A.; Funding - None; Materials - E.D.İ., Y.A.; Data collection \&/or processing E.D.İ., Y.A.; Analysis and/or interpretation - E.D.I.; Literature search - E.D.I.; Writing - E.D.İ, Y.A.; Critical review E.D.İ, Y.A.

\section{References}

1. WHO. Cancer. Available at: http://www.who.int/ mediacentre/factsheets/fs297/en/. Accessed Dec 28, 2019.

2. Stewart BW. World Cancer Report 2014. IARC Publications. Available at: http://publications.iarc.fr/NonSeries-Publications/World-Cancer-Reports/WorldCancer-Report-2014. Accessed Dec 28, 2019.

3. US Preventive Services Task Force. Available at: https://www.uspreventiveservicestaskforce.org/. Accesssed Dec 28, 2019.

4. Tuncer M. Cancer Control in Turkey. Ankara: Koza Printing; 2009.

5. Boyle BL. World Cancer Report 2008. IARC Publications. Available at: http://publications.iarc.fr/NonSeries-Publications/World-Cancer-Reports/WorldCancer-Report-2008. Accessed Dec 28, 2019.

6. Platin N. Cancer Handbook for Nurses. Ankara: 4. Akşam Sanat Okulları Matbaası; 1996.

7. The Lancet Oncology. The importance of nurses in cancer care. Available at: https://www.thelancet.com/ journals/lanonc/article/PIIS1470-2045(15)00066-2/ fulltext. Accessed Dec 28, 2019.

8. Uncu F, Bilgin N. Knowledge, attitude and behavior of midwives and nurses working in primary health services on breast cancer early diagnosis practices. The Journal of Breast Health 2011;7(3):167-75.

9. Cho J, Smith K, Choi EK, Kim IR, Chang YJ, Park HY, et al. Public attitudes toward cancer and cancer patients: a national survey in Korea. Psycho-Oncology 2012;22(3):605-13.

10. Yllmaz M, Dişsiz G, Göçmen F, Usluoğlu AK, Alacacioğlu A. The Study Turkish Version of Validation and Reliability of a Questionnaire for Measuring Attitudes Toward Cancer (Cancer Stigma)- Community Version. Journal of Anatolia Nursing and Health Sciences 2017;20(2):99-106.

11. Gill F, Duffy A. Caring for cancer patients on non-specialist wards. British Journal of Nursing 2010;19(12):761-7.

12. Kearney N. Oncology health care professionals attitudes to cancer: a professional concern. Annals of Oncology 2003;14(1):57-61.

13. Cho J, Choi EK, Kim SY, Shin DW, Cho BL, Kim CH, et al. Association between cancer stigma and depres- 
sion among cancer survivors: a nationwide survey in Korea. Psycho-Oncology 2013;22(10):2372-8.

14. Usta YY, Demir Y, Yagmuroglu H. Nurses' perspective on positive attitudes to cancer patients in Turkey: a qualitative study. Asian Pac J Cancer Prev 2012;13(4):1225-9.

15. Terakye G. Interaction with the patient and his relatives. DEUHYOED 2011;4(2):78-82.

16. Dedeli Ö, Daban UK, Pakyuz SC. Turkish Nurses' attitudes towards patients with cancer. Int J Nurs Sci 2016;6(1)1-6.

17. McCaughan E, Parahoo K. Attitudes to cancer of medical and surgical nurse in a district general hospital. European Journal of Oncology Nursing 2000;4(3):16270.

18. Corner J. The impact of nurses' encounters with cancer on their attitudes towards the disease. Journal of Clinical Nursing 1993;32:363-72.

19. Shahriary S, Shiryazdi SM, Shiryazdi SA, Arjomandi A, Haghighi F, Vakili FM, et al. Oncology Nurses Knowledge and Attitudes Regarding Cancer Pain Management. Asian Pacific Journal of Cancer Prevention 2015;16(17):7501-6.

20.Box V, Anderson Y. Cancer Beliefs, Attitudes And Preventive Behaviours Of Nurses Working In The
Community. European Journal of Cancer Care 1997;6(3):192-208.

21. Yildirim YK, Cicek F, Uyar M. Knowledge and Attitudes of Turkish Oncology Nurses About Cancer Pain Management. Pain Management Nursing 2008;9(1):17-25.

22. Gore J. Providing Holistic and Spiritual Nursing Care. Available at: http://digitalcommons.liberty.edu/cgi/ viewcontent. cgi ?article $=1383 \&$ context $=$ honors. $\quad$ Accessed Dec 28, 2019.

23. Frank-Stromborg M. Instruments for clinical nursing research. Boston: Jones and Bartlett; 1992.

24. Badihian S, Choi EK, Kim IR, Parnia A, Manouchehri $\mathrm{N}$, Badihian N, et al. Attitudes Toward Cancer and Cancer Patients in an Urban Iranian Population. The Oncologist 2017;22(8):944-50.

25. Lebovits AH, Croen LG, Goetzel RZ. Attitudes towards cancer. Development of the cancer attitudes questionnaire. Cancer 1984;54(6):1124-29.

26. Özyürek M. Engellilere Yönelik Tutumların Değiştirilmesi. Ankara: Kök Yayıncılık; 2010.

27. Dallred CV, Dains JE, Corrigan G. Nursing Workforce Issues: Strategically Positioning Nurses to Facilitate Cancer Prevention and Control. Journal of Cancer Education 2012;27(S2):144-8. 